\title{
Pure Isolated Internuclear Ophthalmoplegia
}

\author{
Emina Ogawa, Ryuji Sakakibara, Masahiko Kishi and Fuyuki Tateno
}

Key words: internuclear ophthalmoplegia, MLF, brainstem infarct, MRI

(Intern Med 50: 1785, 2011)

(DOI: 10.2169/internalmedicine.50.5641)
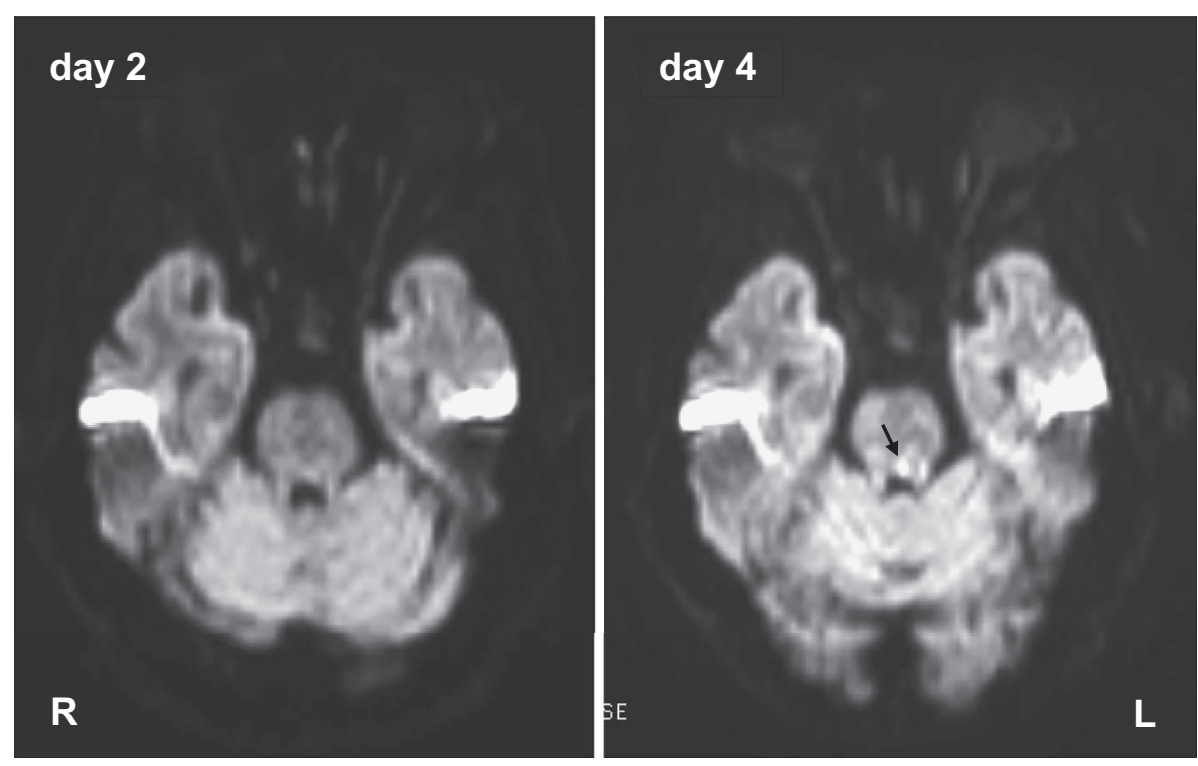

Picture

Pure isolated internuclear ophthalmoplegia from ischemic origin is rare (1). A 76-year-old man with severe aortic stenosis was admitted to our hospital because of sudden onset of horizontal diplopia. His neurological examination was unremarkable except for adductor paresis of the left eye, and unilateral nystagmus of the right eye toward the lateral gaze. His diplopia gradually ameliorated. Serial brain magnetic resonance imaging (MRI) of our patient on day 2 was unable to show specific lesions (Picture, left panel), while brain MRIs on day 4 clearly revealed a lesion (arrow) around the left medial longitudinal fasciculus (MLF) at the dorsal upper pons (right panel) by diffusion imaging. This time course is in accordance with the fact that diffusion imaging in acute infra-tentorial infarcts may have a peak on day 3 or later, in contrast with the fact that diffusion imaging in acute supra-tentorial infarcts has a peak on days 1 and 2 (2).

The authors state that they have no Conflict of Interest (COI).

\section{References}

1. Deleu D, Sokrab T, Salim K, El Siddig A, Hamad AA. Pure isolated unilateral internuclear ophthalmoplegia from ischemic origin: report of a case and literature review. Acta Neurol Belg 105: 214217, 2005.

2. Axer H, Grabel D, Bramer D, et al. Time course of diffusion imaging in acute brainstem infarcts. J Magn Reson Imaging 26: 905912, 2007.

Neurology Division, Department of Internal Medicine, Sakura Medical Center, Toho University, Japan

Received for publication April 11, 2011; Accepted for publication April 27, 2011

Correspondence to Dr. Ryuji Sakakibara, sakakibara@sakura.med.toho-u.ac.jp

(C) 2011 The Japanese Society of Internal Medicine Journal Website: http://www.naika.or.jp/imindex.html 